Journal of CORPORATE RESPONSIBILITY

AND LEADERSHIP

Corporate Social Responsibility in Management

Theory \& Business Practice

\title{
Environmental Strategy in Business: Green Marketing Communication
}

DOI: http://dx.doi.org/10.12775/JCRL.2017.019

\author{
MAURizio LANFRANChi ${ }^{\mathrm{a}}$, CARlo GiannetTo ${ }^{\mathrm{b}}$, \\ FRANCESCO ROTONDO ${ }^{c}$ \\ ${ }^{\mathrm{a}}$ The University of Messina, Italy, e-mail: mlanfranchi@unime.it \\ bThe University of Messina, Italy, e-mail: giannettoc@unime.it \\ 'The University of Messina, Italy, e-mail: francescorotondo49@libero.it
}

\begin{abstract}
Purpose: The aim of the paper is to explore the issues of green marketing and green marketing communication.

Design/methodology/approach: The narrative literature review is a method applied to achieve the aim of the paper.

Findings: The growth of environmental sensitivity is a driving force for change towards new policy tools and environmental economics. Businesses have developed various tools for environmental communication including environmental balance sheets, social reports, and certifications. It is not enough for businesses to communicate generic commitment to environmental protection; they have to integrate the concept of ecology into corporate culture by creating strong environmental policies and environmental ethics that describe the enterprise at all organisational levels. Businesses focusing on the development of green products must not only 'talk ecologically' but also 'be ecological'.
\end{abstract}

Research and practical limitations/implications: The research has an exploratory character since the sample strategy is not probabilistic.

Originality/value: The study can stimulate discussion in the field of green marketing and green marketing communication.

Paper type: literature review. 
Keywords: marketing communication, green consumer, consumer sensitivity, ecological communication, environmental business communication.

\section{Introduction}

There is a growing interest in companies focusing on the respect of the environment to attract the attention of potential consumers and solicit them to conscious behaviours in purchasing choices. The company's actions try to guide the preferences of consumers towards products and services, valued as more eco-compatible than those of competitors. The implementation of green marketing strategies through the use of advertising messages differ according to the type of environmental communication that companies want to put forward to their consumers.

Nowadays, consumers are more concerned with protecting the environment and safeguarding psychophysical well-being. Therefore, in this paper, we highlight the preeminent role that green marketing assumes as an environmental strategy for business. Our study focuses on marketing communication (communication strategy), and particularly on advertisement. The aim of the paper is to explore the issues of green marketing and green marketing communication. Narrative literature review is a method applied to achieve the aim of the paper. First of all, green marketing is defined and discussed. Secondly, the green marketing stakeholders are identified and characterized. Thirdly, a short case of green marketing in Italy is studied. Finally, green marketing communication and its tools are analysed.

\section{Green marketing}

Green marketing studies are considered to be of academic interest and of public interest (Peattie, 2001; Peattie and Crane, 2005; Grant, 2000). The 1990s are viewed as the important period of green marketing with regard to the number product introductions, the amount of media attention and the number of academic manuscripts (Ottman, 1998; Polonsky and Mintu-Wimsatt, 1995). The task of marketing is to bring to the market products that meet the needs of customers and at the same time support communication aimed at highlighting their value in the eyes of 
consumers. Green marketing, however, is a more complex study and requires new management and market strategies to address the challenges associated with the development of ecological products. Green marketing, as opposed to traditional marketing, promotes the factors and intangible values of a product, aiming at achieving two goals i.e. (Leakey and Van Damme, 2014):

- developing high environmental compatibility of products, which have a minimal impact on the environment and satisfy customers in terms of price, service and convenience;

- transmitting an image of high quality that includes environmental sensitivity for product attributes and for the company reputation.

These goals cannot be achieved through traditional marketing strategies, because 'environmental consumerism' reflects both psychological and social changes. Conventional strategies have led companies to add various wording to labels such as 'degradable' or 'does not harm the ozone layer' without paying attention to real implications in terms of development and communication. Taking advantage of the opportunities of 'environmental consumerism' requires a more structured commitment, as it is an attempt to protect oneself and the entire planet by purchasing only ecological products (Garg, 2015; Lanfranchi, Giannetto and De Pascale, 2014a).

'Environmental consumerism' is not a passing trend, in fact, it is since the 1970s that scholars have been talking about it and many researches have outlined the figure of the green consumer. The 1980s were the period of individualism, which was also reflected in consumption behaviours, as things were acquired with the aim of satisfying individual needs. However, the 1990s observed the advent of a form of social conscience, which still today moves individuals to face global problems against which they have no power. One manifestation of this phenomenon is the growing number of consumers whose decisions on the brand to be purchased are based on how the company has exposed itself in environmental and social terms. That is to say whether it has complied with the current regulations on ecology, and if it pursues an appropriate and correct policy of selecting and recruiting staff, etc. The desire for a better world touches all aspects of life: 'environmental consumerism' is not a movement that is limited to safeguarding the environment but it moves towards a more balanced society, which seeks to replace consumption in a materialistic sense, to a simpler way of living. 
Business and consumer communication should have the same principles and spirit, or, in advertising terms, a alignment between the company and the customer should be created (Zhu and Sarkis, 2016). Through ecological communication, companies want to secure a niche market, the niche of the so-called 'green consumers'. 'Green consumers' are characterized by a high level of education and a prestigious social position, they exert a strong purchasing power, but meeting their needs is complex because they are reluctant to give up the quality and functionality of the product. It is to be noted that not necessarily the attributes of an ecological product motivate the buyer to pay higher prices, in fact if they do not meet expectations it is seen as a useless waste of money. The mistake of overestimating environmental quality at the expense of consumer satisfaction is called 'myopia' of green marketing. The Green Gauge report of 2016 shows that the biggest obstacle to the purchase of green products derives from the consumer's view that buying these products means a greater sacrifice due to the higher cost and lower performance, which is not balanced by significant environmental benefits. Market research has shown that it is possible to avoid this myopia through three principles called the 'three C': Consumer Value Positioning, Calibration of Consumer Knowledge and Credibility of Product Claims (Leakey and Van Damme, 2014).

Consumer Value Positioning: Generally, green products must be associated with the benefits: efficiency, convenience, health, safety, performance and symbolism. When it is not possible to have all the benefits, marketing should be able to associate the benefits of the green product to the specific segmentation of consumers that it wants to attract, including the most desired benefits expected by this consumer range (Sadovnikova and Pujari, 2017).

Calibration of Consumer Knowledge: Marketing in this case uses messages and slogans that link the benefits of green products to the desired value of the consumer, i.e. marketing programs must supply the consumer with the necessary knowledge in order to recognize the benefits of the product. In this light, it is necessary to educate consumers with the introduction of messages, that link the environmental attributes of the product to the desired value of the consumer (for example, "products without pesticides are healthier”, "energy efficiency is a saving”, etc.). All this is to make it clear that these products are a solution to meet customer needs (for example, "rechargeable batteries offer longer service”) (Zhu and Sarkis, 2016). 
Credibility of Product Claim: Credibility is the foundation for an effective green marketing action. Therefore, it is necessary to support the environmental benefits that the consumer obtains from the use of the green product through specific actions. Messages must be specific, meaningful and qualifying, for example, by comparing them with similar products. It is necessary to obtain approvals and eco-certifications for the product, from accredited bodies, make consumers aware, as in the case of "Coldwater challenge". Therefore, the green approach should not be considered as a shortcut, but as a challenging road (Voinea, Atanase and Schileru, 2016; Leakey and Van Damme, 2014).

\section{Green marketing stakeholders}

A green consumer can be defined as the one who actively seeks products with a relatively low impact on the environment (Ottman, 1998). Educated, well off, informed, he is the most appealing target. Green consumers contribute to cleaning and preserving the environment, especially through their behaviours related to the specific product, for example, recycling materials and purchasing products that are perceived as ecological. In the decision-making phase, they want to know exactly how to identify ecological products and where it is possible to find them. Commitment to environmental issues can be segmented according to lifestyles. Four segments can be identified in the population, depending on the different level of environmental commitment (Peattie and Crane, 2005). The 'purist' have deep environmental convictions and act accordingly. Within the environmental population they are the most mature (over forty), the richest, six out of ten are women, they believe that their personal action makes the difference. Their social influence is bound to exert more and more importance. The 'materialists' support the environmental movement but are too busy to change lifestyles. They express their views on the environment by making money donations and paying high prices to buy ecological products. They are people with a high level of education. The 'immature' people confirm the need for greater legislative intervention in favour of the environment, but they do not believe they can do much at a personal level. They show indecision in the choices between environment and economy (Finch, Geiger and Harkness, 2017). The 'immature' believe that the problem does not concern them 
and that someone else will solve it. They are poorly informed and confused on environmental issues. The 'indifferent' represent the largest and the least involved group. They are convinced that they cannot do anything to solve the environmental problems; they are, in most cases, the poorer class (Rahnama and Rajabpour, 2017).

The new terminology used in advertising (recyclable, biodegradable) suggests that attention has been shifted from the product attributes (non-toxic, non-irritating) to immediately non-controllable factors such as processes, the choice of raw materials, and the disposal of the product. Green consumers have to feel, even if only symbolically, that they are able to do something, as they show the will to take on the responsibility of their actions. When, in fact, the consumer identifies environmental damage that he could keep under control, but for which he does nothing, it increases his sense of guilt and he tries to compensate the best way he can. The consumer's concern cannot be satisfied through a superficial improvement of the products and/or communication (Zhu and Sarkis, 2016).

Businesses focusing on the development of green products should not only 'talk ecologically' but also 'be ecological'. It is no longer enough to communicate its generic commitment to protecting the environment in order to provide a satisfactory response to the demand of consumers. Companies must integrate the concept of ecology into their business culture. In fact, it is only through the creation and implementation of strong and serious environmental policies, that products and services that will best protect the environment can be developed. Finally, yet importantly, by creating environmental ethics that reward the enterprise at all organisational levels, it will be possible to activate marketing and communication strategies that respond to the consumer's expectations (Finch et al., 2017).

Marketing must aim at well-informed consumers who have the right tools to make the decision to purchase. Many companies have already started advertising campaigns to influence the process of changing attitudes and behaviours. Consumers have a considerable role as a reference audience; their buying behaviour is a function of their perceptions. For this reason, it is important for companies to ensure consumer support. The wrong perception of real problems can mean a loss of opportunities. Packaging, for example, is an increasingly important topic for the solid waste problem; excessive packaging can become a very bad attribute for a brand (Sadovnikova and Pujari, 2017). 
Government bodies are not an obstacle to business development, to the contrary, they collaborate with businesses, and this collaboration allows access to technical data and resources that can open up new marketing opportunities. The voters are continually urging the administrative authorities to deal with the environment, above all, by putting pressure on the industrial sector considered to be the major source of pollution. The polluter pays principle is increasingly successful even if, at times, legislators do not have the technical knowledge or business processes necessary to ensure the best results (Finch et al., 2017).

Environmental groups tend to develop alliances with businesses that show attention to environmental issues, so, for companies, there is a growing credibility among consumers and the media with an increase in the market impact. Over the last thirty years, environmentalists have become watchful observers and sophisticated communicators, they have organised themselves in large national and international associations, and some are very skilled in exploiting the media. The citizens, who perceive them as 'non-extremists', appreciate their commitment. Often, they launch boycott campaigns against companies that pollute, distribute books with lists of 'ecological' brands, and they seek a dialogue with companies and legislators. Operators, who create constructive relationships with environmentalists, can expect long-term significant returns, because environmental organisations will play an increasingly important role in raising awareness among consumers. Then, thanks to the increased social awareness they will have no difficulty in bringing experts and professionals to their point of view by strengthening their commitment and credibility. As environmental groups exert an influence on the media and consumers, it is important for industries to get their approval before a product is launched on the market. They can obtain the collaboration and the necessary support, by sponsoring ecological initiatives or setting up roundtables of discussion. These serve to share the information to fully understand the opinions of both sides, and come to satisfying and practicable solutions. Retailers, in order to take advantage of the loyalty of their customers, activate recuperating and recycling programs at retail outlets and consult auditing companies to test the ecological safeguards offered by the companies (Mohd Suki, 2017).

Children and adolescents represent both a strong purchasing power and a group that can influence parents' decisions - in fact, they can lead them to recycle, to buy ecological products, and to avoid certain 
brands. As they are future buyers, it is good to establish positive relationships with them. If children are ecologically sensitive, their decisions will be experienced in workplaces, elections, as well as in supermarkets. The role of educators is important: as habits are defined in the early stages of life, if a child is taught the right answers, as an adult they will make the best decisions (Lanfranchi, Giannetto and De Pascale, 2014b).

The media follow ecology disasters and are timely in communicating them: oil spills, big fires, and animal massacres are hot news topics. Environmental issues seem to be treated with seriousness, which is important because consumers get most of their information on the state of the environment from the media (and especially from television). Many journalists, however, are not experts on the subject and rarely provide all the news to give a comprehensive report to facilitate balanced decisions. It is therefore in the interest of companies to collaborate with the media by providing them with all the information they need to make the problem fully known and thus avoiding negative effects in terms of turnover. In order to gain media support, companies can provide technical support to reporters or communicate them their own business strategies and initiatives. Businesses cannot lose public support: developing solutions to environmental issues requires the company's commitment, but also the support of all the external sectors (Sadovnikova and Pujari, 2017).

It is not enough for businesses to communicate their generic commitment to environmental protection; they have to integrate the concept of ecology into their corporate culture by creating strong environmental policies and environmental ethics that describe the enterprise at all organisational levels. In addition, in advertising, there is no common green marketing terminology. The lack of collaboration between industry, government bodies and the scientific community creates confusion among consumers and hampers effective communication. Being able to communicate the benefits of green products can be a very difficult task, often due to the fact that the benefits are not tangible and they are not perceived in the short term. Communicating these benefits is effective through advertising, whether through public relations, or if implemented by the retail chain. Conquering a good environmental image serves to increase sales and avoid legislative action. 


\section{Case study: green marketing in Italy}

In recent years, in Italy, the presence of references to ecology and advertising has become increasingly important. More, and more, companies are focusing on the respect of the environment to attract the attention of potential consumers and encourage them to conscious behaviours in their buying choices, trying to direct their preferences towards products and services, considered as the most eco-compatible compared to those of the competitors (Lanfranchi, Giannetto, and De Pascale 2015b).

The realization of green marketing campaigns using advertising messages differs according to the type of environmental communication that companies use to address their consumers. In some cases, ecological advertising comes from a very intense commitment to the environment, which has been translated into deep product innovation and is based on the credibility of an external certification. It should be noted, however, that usually, ecological advertising is implemented through simple cosmetic changes of the corporate image driven by market opportunities linked to increased consumer sensitivity. It is not the result of a strategy of environmental improvement of products, which remains very superficial and dominated by the need to focus on more traditional marketing variables (quality, performance, and price). This is because when companies are only superficially involved in protecting the environment, they are unwilling to centre their message on a dimension that is not a real strength, nor does it make it a major source of confrontation with competitors. It is also evident that companies are more likely to value only ecological benefits of the product, while environmental impacts (often more relevant) appear more marginal in relation to the production processes and other business activities. An example of the exception is the new advertising campaign of Valfrutta Conserve Italia, which to prove its care for nature, in advertising boasts of using only wind power. Among the most frequently highlighted aspects of eco-advertising, we can find energy savings to be obtained from the use of the product, benefits associated with the re-use of materials (e.g. paper) as a component of the product or the possibility to recycle the product, the atmospheric emissions, and the use of biological raw materials (in the case of food) (Finch et al., 2017).

It should be noted that often green advertisements are excessively generic, superficial, and incomplete information is provided to the 
consumer. The eco-friendly message should be clear (for example, by avoiding the use of technical terms which are difficult to understand), but at the same time accurate, complete and relevant to environmental aspects. Therefore, the issue of the details and information provided by the eco-friendly message is of great importance as is the proper use or how to recycle a product at the end of its life. In the Italian context, there is almost no advertising that offers environmental comparisons, few companies offer comparisons to the benefit of consumers, for example by comparing it with industry averages (Lanfranchi, Giannetto and De Pascale, 2014c).

Very often, ecological advertising is characterized by a multidimensional approach, in which the green message is accompanied by more or less marked references to other aspects, especially those related to health and safety of the individual. This depends on the tendency to enhance the 'proximity', that is, by attempting to leverage impacts closer to the individual, which can therefore increase his attention. Only in a limited number of cases, advertising focuses on environmental issues, without the need for a more or less direct link to performance or effectiveness. This is due to the fact that even consumers who include environmental quality among the parameters that influence their purchasing process they are not willing to give up traditional quality or pay a higher price to receive the ecological quality of the product. It is interesting that women are the most represented category of people taking part in 'green' advertisements, who are able to enhance the message on the respect of the environment. This is due to the belief of many companies that young mothers are the most sensitive market segment on ecological issues. Surprising is the low presence of young people and adolescents, as the eco-friendly message usually takes into account the public's concerns of the environment which they are exposed to and the reflections that this situation may have impact on people and their health. A greater presence of young people would be expected, both because they are at risk, able to move collective awareness, and because future generations are more interested in a cleaner environment (Lanfranchi, Giannetto, Abbate and Dimitrova, 2015c). 


\section{Environmental business communication}

The growth of environmental sensitivity is a driving force for a change towards new policy tools and environmental economics. Businesses have developed various tools for environmental communication, among which the most important is the environmental balance sheets. These tools have facilitated the transition from a responsive system (response to information requests) to a proactive system (which defines an environmental communication strategy), and have proved to be suitable to communicate, over time, the evolution of the commitment made. The environmental communication is a decisive moment in green marketing, as it is the expression of the company's integrity and reliability. Message content must be relevant, as a whole, to the environment. The publicity channel and the message form vary according to the recipient and the promoter. Traditionally, the category of recipients includes businesses, public administrations, environmental groups, citizens, associations (cultural or political). However, there is observed an exchange of roles, so there may be a situation where the public administration (promoter) is found to be the recipient (Sadovnikova and Pujari, 2017).

In general, in the documents that describe the relationships between businesses and the environment, there is quantitative information (environmental data and indicators) and qualitative information (actions, programs and goals). It is important that the language used is functional for the target audience, which describes the data collection criteria and the state of the environment with respect to the parameters influenced by the activity. Business environment communication can be traced back to three types of messages (Garg, 2015):

- propositional communication (to inform);

- reaction statement (if the firm suffers from the pressure of groups such as shareholders, legislators and, in general, interest bearers; the pressure will be proportional to the size of the company);

- communication of the response (above all, those requested by the public administration).

The fact that, in the environmental information, environmental balance sheets have been included (costs and losses or income and profits that arise from the influence of the company on the environment and all the information needed to make the environmental accounting entries 
intelligible) indicates, on one hand, that the needs of the community are transformed, and on the other hand, that the business world is aware of its social role and of the importance of transparent information. Describing environmental activities within the budget is an opportunity to divulge a positive image to a greater number of recipients than the institutional ones. The presence of promotional messages within the budget (regarding ecological products or protection actions) can contribute to possible repercussions on the company's economic value (Mohd Suki, 2017).

Business environment communication in the future will need to be integrated horizontally (with the usual forms of corporate communication), vertically (requiring the contribution of all levels of enterprise organisation) and transversally (involving all business functions from accounting to marketing). If environmental communication were to be mandatory, it would probably take a very similar form to environmental relations, which often use a technical and non-disseminative language. In addition, environmentalists, non-government organisations, consumer groups and various associations cannot force the company to provide information on a continuous basis: they lack a statutory sanctioning power, and therefore their requests are attributable to voluntary communication. The forms of non-compulsory environmental communications (it is the business, that decides if, how and what to communicate) are: environmental communication documents, that is, true image of operations with which the company refines its marketing techniques; and documents, which are synthetic presentations of activities, data, indexes and commitments for the future. These documents are the result of various consultations within and outside the company. Employees, managers, shareholders, customers, suppliers are all called to discuss environmental and social issues. If the enterprise is not subject to communication restrictions, it will be stimulated to create more effective and sensational forms of communication (Zhu and Sarkis, 2016).

\section{Environmental appraisal and accounting}

Environmental appraisal is an instrument of managing and controlling business activity as well as supporting company communication aimed at stakeholders concerned with ecological matters (Mohd Suki, 2017). An accurate communication strategy must, in fact, make a stakeholder 
aware of the degree of ecological compatibility achieved by processes and products and document the efforts made and envisaged in the field of environmental protection. In this regard, eco appraisal, as an information system dedicated to the control of environmental performance, plays an essential and indispensable role (Lanfranchi, Giannetto, De Pascale and Hornoiu, 2015a).

The environmental budget is, according to the definition of the ENI Enrico Mattei Foundation, “the accounting instrument capable of providing an organic framework of direct interrelationships between the enterprise and the natural environment through the appropriate representation of quantitative and qualitative data on the environmental impact of productive activities, and of the economic and financial effort sustained by the company to protect the environment”. It is a collection of synthetic frameworks that contain information on the environmental aspects of the company, which are drawn up following the simple representation of the environmental data collected over a definite period of time, usually a year. Proper budgeting points to the existence of an information system that allows a periodic collection of significant data on incoming physical flows (consumption of natural resources, water resources, energy consumption, and other) and outbound flows (atmospheric emissions, waste, water discharges, sound emissions, and other). This goes beyond the surveying activities carried out by the company for the fulfilment of legislative requirements, which are therefore not sufficient for the environmental report (Peattie and Crane, 2005).

Balance sheets vary starting from the synthetic ones to the more analytical ones, depending on the degree of accuracy in identifying environmental costs (Matisoff, Noonan and Mazzolini, 2014). The first category, labelled as 'mild green', is characterized by minimized information on the environmental costs incurred by the company, often simply derived from the reclassification of the financial statements, in a way that demonstrates the company's sustained effort to safeguard the environment. If we combine environmental accounting, which is normally done by businesses to physically assess the pollution produced, and the changes in the recipient bodies and the use of environmental resources through various indicators, a clear step is taken towards clarity. In this way, pollution damages are quantified to give them a possible monetary valuation. This ecological accounting configuration is defined as 'dark green'. Its fundamental feature is the extreme analyticity and representativeness of the company's environmental positioning. The 
environmental appraisal can then be considered from another point of view, according to the scale. In fact, it is possible to have product analysis, plant statements, input-output statements, and total statements, in relation to the company's overall business. At present, several large companies produce environmental appraisals. However, there is no official standard reference scheme, so the eco-balance sheets appear in an extremely different form. Some point out, with a mere descriptive relationship, the environmental policies pursued by the company. Others have ecological accounts and cash flows statements alongside it (Moser, 2016).

\section{Conclusions}

Everyone needs to review their relationship with the ecosystem: companies maximizing the relationship between product value and resources used and adopting a proactive attitude towards the environment, institutions by promoting the spreading of sustainable development policies and models, citizens by modifying their eco-friendly behaviours in terms of recycling/re-use and eco-friendly purchasing. The idea that information plays an important role in determining environment strategies in business seems to be promising. If it is accepted that consumers will form rules regarding the environmental compatibility of certain substances and production processes, in order to enable green consumerism to function, it is not necessary for each consumer to calculate the environmental impact of the products they buy, it is enough that they know the content and the production technology. Environmental groups are increasingly gathering and spreading this kind of information to encourage businesses to behave more environmentally friendly. This situation can have consequences on the industrial structure. It is very important as companies that have a positive environmental reputation will gain definite advantages over their competitors that do not have the same reputation. This means that the companies that are more environment friendly have better returns than their competitors that are not eco-friendly. Assuming that the theory of green consumerism is useful in understanding the behaviours of businesses, and appropriate analytical tools are developed to model it, the result would be making an environmental policy to gather and circulate information and then to let the market forces lead companies to a more respectful environmental 
friendly behaviours. The instrument that could most contribute to the creation and consolidation of corporate identity is therefore represented by communication. Communication should be managed so that the identity of the company coincides with the perception that customers have of it.

\section{References}

Finch, J.H., Geiger, S., Harkness, R.J. (2017), “Marketing and Compromising for Sustainability: Competing Orders of Worth in the North Atlantic", Marketing Theory, Vol. 17, Issue 1, pp. 71-93.

Garg, A. (2015), “Green Marketing for Sustainable Development: An Industry Perspective”, Sustainable Development, Vol. 23, Issue 5, pp. 301-316.

Grant, R.M. (2000), The Greening of Business: The Role of Green Consumerism, the Limits of Earth, and Generation X, doctoral dissertation, Department of Marketing, University of Southern California.

Lanfranchi, M., Giannetto, C., De Pascale, A. (2014a), "Effects of Drought on the Agricultural System: An Analytical Approach Based on the Production Function”, Applied Mathematical Sciences, Vol. 8, No. 104, pp. 5155-5162.

Lanfranchi, M., Giannetto C., De Pascale, A. (2014b), “A Consideration of the Factors Influencing Tourism Development in Relation to Biodiversity Conservation”, WSEAS Transactions on Business and Economics, Vol. 11, pp. 508-513.

Lanfranchi, M., Giannetto C., De Pascale, A. (2014c), "Economic Implications of Climate Change for Agricultural Productivity”, WSEAS Transactions on Environment and Development, Vol. 10, pp. 233-241.

Lanfranchi, M., Giannetto, C., De Pascale, A., Hornoiu, R.I. (2015a), “An Application of Qualitative Risk Analysis as a Tool Adopted by Public Organizations for Evaluating 'Green Projects’”, Amfiteatru Economic, Vol. 17, Issue 40, pp. 872-890.

Lanfranchi, M., Giannetto, C., De Pascale, A. (2015b), “The Link Between Economic Growth and Environmental Quality in the Case of Coastal Tourism in the Rural Areas”, Applied Mathematical Sciences, Vol. 9, No. 35, pp. 1745-1755.

Lanfranchi, M., Giannetto, C., Abbate, T., Dimitrova, V. (2015c), “Agriculture and the Social Farm: Expression of the Multifunctional Model of Agriculture as a Solution to the Economic Crisis in Rural Areas”, Bulgarian Journal of Agricultural Science, Vol. 21, No. 4, pp. 711-718.

Leakey, R., Van Damme, P. (2014), “The Role of Tree Domestication in Green Market Product Value Chain Development”, Forests Trees and Livelihoods, Vol. 23, No. 1-2, pp. 116-126.

Matisoff, D.C., Noonan, D.S., Mazzolini, A.M. (2014), "Performance or Marketing Benefits? The Case of LEED Certification”, Environmental Science and Technology, Vol. 48, Issue 3, pp. 2001-2007.

Mohd Suki, N. (2017), “Green Products Usage: Structural Relationships on Customer Satisfaction and Loyalty”, International Journal of Sustainable Development and World Ecology, Vol. 24, Issue 1, pp. 88-95. 
Moser, A.K. (2016), “Consumers’ Purchasing Decisions Regarding Environmentally Friendly Products: An Empirical Analysis of German Consumers”, Journal of Retailing and Consumer Services, Vol. 31, pp. 389-397.

Ottman, J.A. (1998), Green Marketing: Opportunity for Innovation, NTC Contemporary, Lincolnwood.

Peattie, K. (2001), “Towards Sustainability: The Third Age of Green Marketing”, The Marketing Review, Vol. 2, No. 2, pp. 129-146.

Peattie, K., Crane, A. (2005), “Green Marketing: Legend, Myth, Farce or Prophesy?”, Qualitative Market Research: An International Journal, Vol. 8, Issue 4, pp. 357-370.

Polonsky, M.J., Mintu-Wimsatt, A.T. (1995), Environmental Marketing Strategies, Practice, Theory, and Research, The Hawthorne Press, New York.

Rahnama, H., Rajabpour, S. (2017), "Identifying Effective Factors on Consumers' Choice Behavior Toward Green Products: The Case of Tehran, the Capital of Iran”, Environmental Science and Pollution Research, Vol. 24, Issue 1, pp. 911-925.

Sadovnikova, A., Pujari, A. (2017), "The Effect of Green Partnerships on Firm Value”, Journal of the Academy of Marketing Science, Vol. 45, Issue 2, pp. 251-267.

Voinea, L., Atanase, A., Schileru, I. (2016), "Perceptions of the Slow Food Cultural Trend Among the Youth”, Amfiteatru Economic, Vol. 18, Issue 10, pp. 847-861.

Zhu, Q., Sarkis, J. (2016), “Green Marketing and Consumerism as Social Change in China: Analyzing the Literature”, International Journal of Production Economics, Vol. 181, pp. 289-302. 